\title{
LAS PEDANTERÍAS QUE NOS PIENSAN
}

Carina Rattero ${ }^{\mathrm{i}}$

\section{Las pedanterías que nos piensan.}

Pedanterías son todas esas formas de conducir la existencia humana sin inquietarla, sin ponerla en cuestión, sin llevarla más allá de sí misma. Pedagogía y pedantería comparten esa raíz ped - pie, el que anda a pie, como guiar o conducir. Por esto, la pedagogía porta cierta arrogancia, pretende saber lo que al otro le conviene, "lo lleva a donde quiere o le dice lo que ha de hacer" ${ }^{\text {,ii }}$ Pedante es el que hace alardes de sabihondo, el que se pretende erudito. El que se sostiene en la soberbia que pretende determinar el qué de cada cosa, y que hay que hacer con ellas.

«"El mayor hechicero (escribe memorablemente Novalis) sería el que hechizara hasta el punto de tomar sus propias fantasmagorías por apariciones autónomas. ¿No sería este nuestro caso?" Yo conjeturo que así es. Nosotros (la indivisa divinidad que opera en nosotros) hemos soñado el mundo. Lo hemos soñado resistente, misterioso, visible, ubicuo en el espacio y firme en el tiempo; pero hemos consentido en su arquitectura tenues y eternos resquicios de sinrazón para saber que es falso.» De este modo, Borges nos recuerda, por si acaso, si no sería este nuestro caso.

El mundo de la pedagogía, el de la escuela, parecieran demasiado poblados de clichés que ya no se interrogan: repeticiones, rituales, convenciones y verdades se nos dan como algo evidente. Ilusiones verdaderas, metáforas que en el uso reiterado y compartido se presentan como expresión de las cosas -"tal y como son". iii

Es que el horizonte discursivo de la educación se ordena al mundo administrado, nominaciones y categorías toman sus propias fantasmagorías por apariciones autónomas. "Hemos perdido la conciencia y el sustrato imaginario del símil que hacía vero-símil la metáfora, y lo que era vero-símil se nos ha quedado en simple 'vero', verdad pura y simple, es decir, purificada y simplificada del magma imaginario del que emergió." (LIZCANO, 2009: 62.)

"Denso en todas partes" lo imaginario permanece inextirpablemente unido a cualquiera de sus emergencias, sus pistas pueden, por tanto, rastrearse en cualquiera de sus formas instituidas: la metáfora, la imagen, la creencia... en esos tenues y eternos resquicios de sinrazón... 'ebullición', ‘manantial', ‘torrente’, ‘raíz común’ o ‘agitación subterránea', lo 
imaginario es actividad antes que acto, verbo antes que sustantivo, potencia antes que dominio, presencia antes que representación...

Los imaginarios pedagógicos son ese sustrato del que se alimentan sentidos, significaciones y comportamientos; lugar de creatividad, pero también su límite. El cerco o frontera dentro del cuál se despliegan en un momento dado, sus posibilidades de imaginación y reflexión, de producción de novedad, como de consolidación y repetición de prácticas... Lo que en cada caso puede o no verse, lo que puede o no pensarse y lo que puede o no decirse o hacerse...

En esa doble dimensión se asegura para la educación tanto su disposición para afirmarse en lo que es - es decir, la continuidad que permite recrearse en sí misma-, como su posibilidad para crear formas nuevas...

Teniendo en cuenta que los discursos desde los que se organiza la escena educativa tienen central imbricación en la configuración de las prácticas, atender a las lógicas desde las cuales se organiza la formación, como a los supuestos desde los que los profesores refieren a su propia experiencia, intenta visibilizar ciertos centramientos y problemas para pensar de otro modo las relaciones de conocimiento y el vínculo entre generaciones en la experiencia educativa. En este sentido va esta apuesta que se ensaya en la escritura, merodeando esos regimenes de visibilidad en el orden del discurso pedagógico: las pedanterías que nos piensan.

\section{Pendanterías enamarcantes.}

"Muchas miradas no son, así pues, sino los instrumentos de una sola finalidad miro lo que busco y finalmente (...) no veo más que lo que miro” (BARTHES, 1982; 309) Un pensamiento "enmarcante",iv actúa como visor. Visor es una palabra ligada a visión, a dispositivo óptico, enfocar, hacer foco, ver. El diccionario aporta significaciones: un prisma o sistema óptico como el que llevan ciertos aparatos fotográficos, que sirve para enmarcar. En algunas armas de fuego, el visor ayuda a establecer la puntería o a corregirla'.

La pedantería "enmarcante" permite enfocar rápidamente produciendo un modo de ver que pretende de antemano saber lo va encontrar, interroga como si no supiera, aunque esté desde su formulación precedida por las respuestas. Al focaliza desde el deber ser, o desde cierta representación de lo general, encuentra así en lo singular apenas el desvío, su fracaso o el escándalo... 
Se trata entonces de pensar como se construye nuestra visibilidad en esta escasez de miras, en esta modalidad universalizante y correctiva. Foucault ha puesto en evidencia la observación sistemática y sistematizada de cualquier aparato disciplinario.

El examen es un ejemplo de esto, es un dispositivo de visibilidad. Un problema relevante analizado por Foucault, es cómo determinar en un mismo movimiento lo que es visible y el ojo que ve. Una maquina óptica determina y constituye a ambos. Es decir un régimen de visibilidad, un conjunto de máquinas ópticas abren el objeto a la mirada y abren el ojo que ve. Determinan que algo se ve (y se hace ver) y a la vez el alguien que ve o hace ver) Esto aunque es siempre histórico y contingente, resulta central para pensar esta pregunta. ¿Qué miramos cuando vemos?

Los modos de conocimiento de la modernidad ilustrada configuran una poderosa trama que ordena nuestro modo de ver: podemos enumerar entre otras, las pretensiones de claridad y distinción, de abstracción, la búsqueda de objetividad y universalidad. La realidad o el lenguaje como representación o des-cubrimiento de unos hechos que parecieran estar ahí fuera.

Esta trama construye desde la pedantería, haciendo como si no supiera, que cada dato, cada hecho, o concepto nunca es un 'mero dato', un 'hecho desnudo', un 'concepto puro', que cada dato, cada hecho, o concepto está cargado con las significaciones imaginarias que lo han hecho, in-corporando en su propio cuerpo los presupuestos desde los que ha sido pensado, las significaciones y disputas cristalizadas como un el tejido de escombros o restos...

Nochecita de martes, Facultad Ciencias de la Educación. Clase de didáctica. Los vidrios empañados, las ventanas cerradas por el frío de junio, no impiden sin embargo oír las campanadas de la iglesia cuya torre deja ver el ventanal del tercer piso. Dan las veinte y quince. Ayelén, estudiante de 4to año, sube la voz. Lee sus anotaciones. Son impresiones y reflexiones sobre una clase de Psicología del aprendizaje durante su estancia en una institución de Formación docente:

\footnotetext{
Los alumnos, ante la consigna de 'poner en tensión los aportes teóricos trabajados durante las clases con lo observado en las escuelas que visitaron', intentan "reconocer", "identificar" en las observaciones las categorías trabajadas. Habita un modo de lectura en el que se intenta "aplicar" las categorías a las prácticas observadas, se hace un esfuerzo por "analizar" (como sinónimo de descomponer) todo lo que sucede, buscando a veces de modo forzado encontrar allí las categorías y dejando de lado lo apasionante de preguntarse, lo no dicho, lo no comprendido... ${ }^{\text {i }}$
} 
El relato trae testimonio de estas comprensiones en la enseñanza. El modo solicitado de aproximación al conocimiento, su modo de producción escolar - en esta situación al 'trabajo de campo'-, ofrece 'una serie datos sin sorpresa' y amordaza la visibilidad del acontecer 'dentro' de 'marcos teóricos' que ya lo tienen todo dicho. Una óptica que busca comprender y encontrar significados estables, mediante 'la aplicación desabrida de una masa inerte de conceptos a una colección de datos que casi siempre están preparados para satisfacer las más irrelevantes obviedades”. (GONZALEZ Y OTROS, 1994:5)

Los 'conceptos' constriñen, maniatan, unifican. Así aquello que vendría a explicar, aquello que vendría a hacer comprensible una serie 'hechos observados'- aun a riesgo de forzar las correspondencias- hace olvidar las diferencias y sutilezas en una representación que promete ser la verdad (de esos hechos o datos). Aplicando este modo enmarcante, la casta pedagógica produce una mirada segada al mandato de "hacer visible lo real", al deseo de ver claro, la preocupación por definir, comprobar, tener bajo control las distorsiones...

Desde la operación de cierre que realiza el concepto, el intento tener bajo control las significaciones de su lenguaje, la pretensión de fijar identidades reconocibles.... y todas esas pedanterías que se dirigen a otro diciéndole cómo tiene que ver el mundo y qué debe hacer... Un modo de didactizar que nos da el mundo ya pensado, como objeto de un mero reconocimiento. Se ordena en esa doble ilusión: la imnediatez de "lo dado", como posibilidad de apresar la realidad en indicadores precisos; y la de un lenguaje claro - sin ambigüedades ni polisemias- que abrocharía un significante a un significado. Es esta pretensión la que regula las prácticas de enseñanza, del concepto a la realidad, de la teoría a la práctica, la prescripción del acontencer, enmarcando en indicadores claros y precisos, señalando criterios de claridad y precisión, pretendiendo que los estudiantes "respondan adecuadamente a las consignas...." y tantos más.

Al constituírse bajo la marca del conocimiento científico, el discurso pedagógico va organizando un orden y una visibilidad que se configura como parámetro de vigilancia epistémica y corrección de las prácticas. La enseñanza se ordena en este diagrama, e intenta definir su identidad en el efecto poderoso de estas metáforas. Una idea de control y dominio intenta gobernar a la acción- "conducir la clase", "tener manejo de grupo", "llevar el programa a buen puerto"... Sometiendo el hormigueo viviente, a los dictados de la planificación, al control exhaustivo de tiempos y movimientos, dejando así, la intensidad del acontecimiento como resto.

En una entrevista que realicé hace un tiempo relataba una maestra: 
"...Cuando me toco preparar la fiesta de fin de año, encaucé mis palabras con una cosa que me dijo una directora cuando yo me recibí. Ella dijo: 'Marisa, este es su barco, su tripulación, hágase a la mar...' Esas palabras (...) no me las voy a olvidar nunca más.... Es decir es un barco, si yo al barco no lo conduzco bien, si no tengo una habilidad para soportar todas las travesías, las tormentas, los vendavales, los errores,... yo no voy a llegar a buen puerto..."

\section{Prédica pedante: Objeto - Sujeto - Predicado.}

Silvana, estudiante de profesorado se acerca a una escuela secundaria pública para hacer una experiencia. En su primera visita es advertida: "este grupo es terrible", "viste como son éstos, no te dejan desarrollar nada, si vos querés, podes elegir aquel grupo que son más lentos pero no tan bulliciosos"vii

Nombrar y clasificar. Capturar los sentidos, representarnos de manera evidente las cosas y el mundo. Quien impone los nombres controla lo nombrado. Relata Lizcano que los emperadores chinos, que de esto sabían, solían tener a mano un especialista en nombres y etiquetas.

En el campo educativo este lugar muchas veces es ocupado por el "experto" - el especialista -otras tantas por el docente. Revestido por la pretensión de neutralidad y en la presunción de un punto de vista no contaminado u omnicomprensivo, el que administra los nombres se consolida en el modelo de dominio moderno y se autoriza como portador del saber de "la ciencia" o "la verdad".

Un modo de significar que construye el sujeto de la pedantería como un sujeto pleno y responsable, conciente de sus proyecciones y realizaciones, que se pone en acto en un modo de relación con el objeto: él es quien focaliza el objeto ("lo dado") y puede dominarlo por la causalidad que "descubre" en su funcionamiento. Es ese yo que representa el mundo, una especie de "supra sujeto" sostenido en las alturas -por la distancia que lo mantiene fuera de la situación estudiada, y que le permite analizar, recomendar y juzgar.

Esta pedantería predica y produce la verdad, verdad del mundo, verdad como realidad, la verdad del texto, del autor, del método, la verdad del aprendizaje y la verdad del sujeto, que es la verdad de una subjetividad... Sabemos el efecto preformativo -creador de realidad- que conlleva el mismo acto de nombrar.

El objeto (ese objeto - que es sujeto objetivado en una relación cosificadora) se constituye desde la parametralización cientificista y la normalización pedagógica, y es censurado o sometido a la penalización, por lo que excede y desborda el concepto o la norma.

Los modos de construir categorías, de percibir identidades o diferencias, los modos de ordenar y clasificar, la manera en que identificamos o nombramos lo posible y lo imposible, 
lo que entendemos y signamos como correcto o incorrecto, tienden a legitimar la mirada del observador. Desde esa posición tan común a la pedantería, que, por su punto de mira "externo" a la situación, puede ver; y desde esa omnipotencia entonces registra "la verdad" de una totalidad, de la cual, supone saber de antemano su movimiento posible.

El lenguaje de nuestra cultura, divide al mundo en sujetos y predicados. Gramaticalmente consideramos que los predicados suceden a los sujetos, y los suceden porque existen los sujetos de los cuales se predica. Nuestra lógica, la lógica que utilizamos para nuestro razonamiento está basada en dicha dicotomía; es el lenguaje del ser, de la identidad, de los contornos fijos. Este lenguaje del ser tiene sus implicancias en sujetos y objetos. Los sujetos, al asumir una identidad, sujetan el desarrollo de su potencia vital (lo que son capaces de hacer) a los deseos, las ideas y las formas de vida propios de esa identidad que se les incorpora.

Los contornos fijos que la identidad delimita, cancelan el puede ser, lo que cambia, el devenir.

\footnotetext{
"Nada hay que no tenga su es ni nada que no tenga su puede ser. Y el es de cada cosa no sería sino el nombre que se ha asumido para ella, en tanto que su puede ser duerme en su interior a la espera de que el establecimiento de un nuevo nombre para ella lo despierte" (LIZCANO, 2009:124).
}

\section{Pedanterías y esterotipos.}

El sujeto de la pedantería quiere domeñar, ordenar las cosas y el mundo, encontrar las reglas de su funcionamiento, comprender lo que representan. Intenta así, reducir la ambigüedad y la incertidumbre... Las etiquetas clasifican, ayudan a controlar la zozobra, cuadriculan la experiencia, solidifican lo que fluye. Mediante el proceso de etiquetamiento intentamos hacer del caos, un mundo.

Los imaginarios operan también como el lugar del pre-juicio, es allí donde anidan aquellas configuraciones previas a los juicios y sin las cuales sería imposible emitir afirmación ni negación alguna. Es el lugar de los pre-su-puestos. Es decir, de aquello que cada cultura y cada grupo social se encuentra puesto previamente (pre-) debajo de (sub-) sus elaboraciones reflexivas. Es el lugar de las creencias; creencias que no son las que uno tiene, sino las que le tienen a uno. (LIZCANO, 2009)

Una pedantería ensimismada en su propio bla bla bleo, no hace lugar a ese silencio que se abre para sentir intensamente lo que viene al encuentro, las palabras no dichas, las que 
desdicen nuestro decir... queda de este modo, privada de las posibilidades que se abren allí donde es posible establecer una relación de confianza con los otros y con el mundo. Llena de sí, no hace lugar al devenir.

La literatura, como arte que trasforma el lenguaje y nuestra relación con las palabras, nos enseña a "problematizar como nombramos lo que vemos y como vemos lo que nombramos". Una novela de Peter Hong, titulada Los fronterizos, ofrece a pensar desde la ficción, las sinrazones de esta racionalidad ordenadora. Internados en una institución 'educativa', tres adolescentes Peter, Katerina y August, son sometidos a un plan sistemático de la observación constante y a una serie de pruebas darwinistas que los etiquetan como 'fronterizos'. Seres que, desde la mirada de cierta psiquiatría, se sitúan en la delgada línea que separa la normalidad de la incapacidad mental. En uno de los párrafos, recuerda Peter, el protagonista:

\footnotetext{
A veces Karin Aero se inclinaba detrás de los que cantaban, cuando hacia su ronda entre las filas. Y entonces decía, con una voz muy queda, para que sólo a aquel que estaban dirigidos sus susurros la oyera:

- Excelente.

Eso se llama elogio. Se supone que es una pequeña obra de caridad.

Cuando aquello sucedía por segunda vez, cuando se detenía detrás de alguno de nosotros por segunda vez, se percibía el miedo en aquellos que no habían sido elegidos. No era un gran temor, no se trataba de un castigo físico, sino de un miedo pequeño que tal vez sólo era perceptible para el que no había sido elogiado demasiadas veces en la vida. El temor a no ser tan bueno (...) a no ser merecedor de los elogios.

Sabias que cuando Karin Aero se acercaba, se acercaba un juez. (...) Juzgar y valorar. Era parte importante del gran plan. ${ }^{\text {vii }}$
}

El gran plan de la pedantería. Fabricar al otro. Hacerlo a mi modo, aprisionar su despliegue en el único modo posible de ser. Así la fabricación se constituye en la figura de la continuidad en el tiempo, perfilando los carriles por los que se desliza la construcción del futuro del otro desde una meta o finalidad programable.

Cercando lo particular como "caso" de alguna categoría universal, se acalla lo que no encuadra, se anula su propia posibilidad de transformación. Esas fijaciones, construyen los cimientos en los que reposa un orden excluyente y estigmatizador. El mismo orden en que se apoyan evaluar, juzgar, conceptualizar, etiquetar.

La pedantería se erige así, como un modo de negación del otro, y reincide en diferentes formas de negación de la experiencia. Porque 
"la experiencia es siempre una relación en la que algo otro nos pasa, en la que algo otro nos altera. Y también de la experiencia como alteridad, porque la irrupción de la alteridad es siempre lo que hace que la experiencia sea experiencia, es decir, que nos lleve más allá de lo que sabemos, de lo que queremos, de lo que ya hacemos o decimos" (LARROSA EN SKLIAR Y LARROSA, 2009: 191).

En el silenciamiento de las singularidades subyace una voluntad de gobernar el movimiento, de penalizar de lo imprevisible. Contra todos los estereotipos, lo humano, vibra en permanente metamorfosis, somos siempre en camino. "En contraposición a la identidad substancial, una identidad narrativa contemplaría las mutaciones, las transformaciones, en el plano constructivo de una vida” (MÈLICH EN SKLIAR Y LARROSA, 2009: 89).

Barthes nos enseña que el estereotipo es triste. Es triste dice, porque está constituido por una prótesis que pretende taponar un agujero; pero a la vez suscita una inmensa carcajada: se toma a sí mismo muy en serio; se cree más cerca de la verdad por su indiferencia hacia su naturaleza lingüística: está completamente desgastado y, a la vez, lleno de gravedad. Por eso mantener el estereotipo a distancia, es una tarea crítica, es decir, una tarea que intenta poner el lenguaje en crisis.

Para acercar la pedagogía a la vida, antes que todo concepto, todo saber universal o toda técnica, en es preciso recuperar el devenir de la experiencia, la fugacidad, su fragilidad y singularidad, su carácter situacional. Recordarnos en las palabras de Zambrano (2000, 86-87) la sonrisa de la experiencia ante la ciencia, por la desproporción escandalosa entre la verdad y la vida. "Desproporción que hace, a veces que la vida atemorizada retroceda". Es que no hay 'experiencia' en sentido abstracto; ni siquiera 'experiencia en situación' en sentido abstracto. Hay experiencia(s) concreta(s) en situación(es) concreta(s). "Siempre experimentamos el mundo en situaciones. Nuestro modo de ser en la vida, nuestras relaciones con los demás y con nosotros mismos, (...) nunca se da 'la' situación, en abstracto, sino siempre y en todo momento estoy en 'mi' situación. 'Mi' situación es 'una' situación posible, y esto significa que siempre hay 'otras' situaciones imaginables" (MÈLICH EN SKILAR Y LARROSA, 2009: 86 - 87).

Las racionalidades binarias, la ilusión de transparencia, los estereotipos, las etiquetas y demarcaciones conceptuales, la pretensión de solidificación del sentido, de cerrar la interpretación en torno a un significado doctrinario y unívoco... construyen un diagrama de visibilidad que va dejando fuera de registro la "experiencia”, lo incalculable, el devenir, los acontecimientos... "Pero la mirada siempre busca algo o alguien Es un signo inquieto: singular dinámica para un signo, su fuerza desborda...” (BARTHES, 1982: 306) 


\section{Pedanterías lineales 'procesuales'}

La pedantería enmarca también el despliegue posible. Pone bajo previsión el movimiento, la posibilidad de variación. Una representación fisicalista del tiempo impone su ordenamiento en una serie de continuidades y 'procesos' que no reconocen sucesos ni momentos diferenciados, sino como aquello que es preciso reordenar y articular sin fisuras. Así las compresiones en el campo se ordenan de modo lineal: enseñanza -aprendizaje, teoría práctica, currículo formal- procesual práctico, modelo-ejecución. De igual modo, dentro de esa visibilidad, enseñar o transmitir un conocimiento es poner en acto una serie de operaciones que permitan pasar de la ignorancia al saber, de lo de lo indeterminado a la identidad, de lo vacío a lo completo, de lo confuso a lo claro. El discurso pedagógico organiza sus prácticas de modo controlable, integrándolas así en un orden anticipable.

Por el dominio de la ciencia y en el camino de la técnica, la pedantería marca un modo de pensar y hacer educación, pretendiendo capturar lo enigmático, dominar y anticipar el acontecer en lógica de los progresos, procesos y productos. Así se examinan las distancias y los sujetos, las capacidades y los cuerpos. Esta pretensión de ordenar, definir, sistematizar relaciones, representar los objetos o encontrar correspondencias entre enunciados y datos... se ordenan en la zaga de una tradición que pretende legitimarse produciendo diagnósticos y programas eficaces.

Por el camino del método, la pedantería codifica generalmente 'a priori' el 'cómo' de la enseñanza y el aprendizaje. El método marca un ordenamiento de la práctica que permitiría encarar la tarea de conocer con todas las garantías, un camino que será libre de riesgos.

Da igual si esa pedantería se dice conductista o constructivista, si se llama enseñanza tradicional o activa, directiva o no directiva, si se trata de aprendizajes personalizados o grupales, el campo metodológico en las propuestas áulicas, se traduce en una serie de "pasos" secuenciales para enseñar: actividades de inicio-exploración de ideas previas, búsqueda de información-, momento de explicación o exposición, copia o toma de notas por parte de los alumnos, actividades en grupo.

De manera más o menos convencional -'plantear un problema', 'formular una hipótesis', 'elaborar fichas de lectura',- se organizan y autorizan en una serie de 'pasos' o estrategias didácticas que van reduciendo la aventura intelectual, subsumiendo los recorridos a una cuestión de 'medios 'que permitirían desplegar este movimiento de manera adecuada.

El testimonio una profesora de historia de la escuela secundaria, acerca del modo en que organiza su enseñanza, da pistas para pensar cómo estas racionalidades organizan las prácticas, motorizan modos de hacer: 


\begin{abstract}
"Pretendo siempre partir desde ideas previas que posea el grupo, y a partir de ello, ir dialogando y profundizando, como si fuera una espiral, en los temas. Apunto a ejemplificar, que los estudiantes den ejemplos, o bien desde mi parte, de modo tal que quede clara la explicación. Por lo general, comienzo las clases con la exploración de ideas previas, luego hay una instancia de lectura, y después suelo organizarlos en grupos con alguna consigna para argumentar, o ejercitar a modo de juego de roles en un debate. De tarea, suelo solicitar la búsqueda de alguna información o imagen referida al tema..."
\end{abstract}

Los caminos trazados por estas racionalidades nos llevan interrogar qué posibilidades se habilitan a la escucha del acontecer. Las encrucijadas en las que se encuentran las prácticas de enseñanza, sus limitaciones para que algo de otro orden se encienda alimentando la imaginación, la creatividad, el potencial instituyente en el vínculo con lo desconocido.

"No hay comprensión posible para el hombre sin imaginación” (LARROSA, 2006: 17). La imaginación marcha por los senderos que nos permiten, en cierto modo, reconciliarnos con lo dado, aunque sea hostil, para buscar otros mundos. En un contexto en el cual la experiencia de enseñanza, de aprendizaje se ha obliterado, el extrañamiento cede terreno para la mera aproximación acrítica hacia un mundo que, igualmente, no tiene sentido y pareciera, no se puede modificar.

Ciertos parámetros que antaño se consideraban inamovibles, sólidos e incuestionables se han tornado movedizos, líquidos y dudosos. Ante esta perpleljidad e incertidumbre, la opción es replegarse en lo seguro, en lugar de abrirse a la invención de otros posibles. En un contexto en el cual, al son del desarrollo técnico la standarización y la generalización, se han transmutado en rasgos constitutivos de la percepción y del andar cotidiano, las posibilidades para la experiencia se encuentran limitadas.

La experiencia es siempre en primera persona, una misma situación puede resultar una experiencia para alguien y no para otro. Es por esto un saber de lo singular, que revela la propia finitud. Es allí, en esa experiencia, consciente de su finitud, donde «encuentran su límite el poder hacer y la autoconciencia de una razón planificadora» (GADAMER, 1997:63) Pero en toda experiencia de la finitud hay también futuro, movimiento.

Por otra parte, el imaginario metodológico reafirma una visión del conocimiento como proceso acumulativo, como si se tratara de un andar de pasos firmes y precisos que conducen a una certeza sin sobresaltos. Ni laberintos, ni viajes de final incierto. Pareciera que los espacios educativos son sitios en que correr riesgos- en el sentido de una aventura de pensamiento- es prácticamente imposible. Se trata de "asegurar la adquisición de conocimientos” y evitar por todos los medios “el extravío del que conoce”. Quizás por esto, la 
pregunta se limita a corroborar lo sabido, el conocimiento se posee, la subjetividad se ordena al método. (Rattero, 2013:11)

Así, el control de lo azaroso, de lo accidental y contingente, como reaseguro del camino a la verdad, pre-viene de los peligros del recorrido. Queda hurtada la experiencia, recordemos aquí, experiencia es una palabra que tanto en lenguas germánicas como latinas contiene esta dimensión de travesía y peligro...

Por la vía de la corroboración, se busca justificar esta racionalidad en sus efectos productivos: los 'impactos' en la aplicación, los 'resultados 'en el aprendizaje, en la implementación curricular, o la efectiva aplicación de un programa. Este registro organiza las pretensiones en el campo, una idea de fundamento como fondo de representaciones desde el cual se significa la relación teoría- práctica y la consecuente traducción de este fundamento o marco teórico en acciones concretas en una suerte de continuidad procesual, en la cual la teoría operaría como un discurso propositivo- normativo y la práctica como el lugar de efectivización técnica de respuestas.

La lengua de la pedantería, la nuestra, la del otro es ese territorio no siempre visitado por la pregunta, por el silencio ético, por la hospitalidad. Cuando ya nada nos protege de la intemperie, el lenguaje se instrumentaliza todavía, borrando los trazos de su propio movimiento, intentando despojarse de toda marca subjetiva, dirigiéndose de modo impersonal... Y va configurando así, una red de significaciones que se tejen en un cuerpo neutro, sin marcas, ni sombras.

\section{Despojarnos de pedanterías.}

¿Cómo hacer tajos en ese modo de saber que se pretende colmado de presencias y representaciones? ¿Preservar un espacio en los bordes, o situarse en medio de, entre sus fisuras...? Para liberar la vida del lenguaje del ser y de los juicios trascendentes, Deleuze proponía borrarse, experimentar... Borrarse quiere decir difuminar en nosotros el universal, los contornos fijos, las líneas duras del ser. Para que la vida circule hay que poner en movimiento el territorio... Convertirse en nómada. Pero el nómada no es el exiliado, sino aquel que está en movimiento, porque no quiere abandonar su territorio... El merodeador, el vagabundo, el transeúnte.

¿Podemos vagabundear al interior de la propia pedagogía? Hay que animarse y salir. Ensayar esa rebeldía contra todos los aprisionamientos, es inventar otras metáforas.... profanando los estratos que configuran nuestra identidad, la lógica binaria por la que somos hombre o mujer, niño o adulto, profesor o alumno... Despojarnos de toda esa arrogancia tan 
segura de sí misma, esas pedanterías sabihondas que nos piensan (hacer quizás... que el mundo devenga rosa... ix

Tal vez, se trate de afirmar el movimiento de la vida-experiencia en aquello que siempre sorprende y desborda los límites, en lo que hormiguea y lo que late... Los peligros y los riesgos están del lado del devenir...

"Un educador tiene la posibilidad de habitar la pregunta por el futuro sosteniendo una ilusión. Esa misma ilusión que da consistencia al tiempo venidero o al amor, la que se construye gesto a gesto, sin pedir garantías cuando correspondemos una mirada, o extendemos la mano hacia otro." (RATTERO, 2007:9)

La aventura incita a bordear lo desconocido. Qué es aprender sino aventurarnos a un viaje, un modo de andar sin barandillas en el vínculo a lo desconocido. Salir de lo familiar, de lo ya sabido... Aprender es, entre otras cosas atreverse a subvertir ese modo único, verdadero, pronosticado de ser, es un acto de rebeldía contra todos los aprisionamientos, "la afirmación de una libertad que permite a un ser desbordarse a sí mismo" (MERRIE, 1998: 80) Experimentar otras miradas desde la enorme perplejidad de este tiempo, asumir sus contradicciones, explorar otros recorridos, hacer un ejercicio de pensamiento e imaginación tomando esa manera tan bonita que nos ofrece J Larrosa $(2003,287)$ entre aquella mirada que clasifica y ordena, que pretende determinar el por qué de cada cosa... y una mirada que vive, se mueve, se cruza con otras... Oponiendo a esta visión burocrática, planificadora, objetivante y orientada al dominio, otra visibilidad, la que se sabe fragmentaria, atónita, construida en la ignorancia y la impotencia, pero avezada en los encuentros. Una mirada que se construye y se nutre de múltiples miradas... abierta a las sorpresas, las aventuras, las paradojas, la experiencia....

Y entonces... otra pedagogía va tomando lugar en esa imperceptible vacilación del sentido que el discurso de la ciencia ha conjurado, en las fisuras que el modo tecnicista no colma. Una mirada y una escucha atentas, que se nutren de perspectivas múltiples, explorando las situaciones, buscando convertir en desconocido lo demasiado conocido, otorgando cierta oscuridad a lo que nos parece claro...

Una mirada que intenta percibir las cosas por el medio - lo que sucede a ese directivo, a ese maestro o profesor y a cada uno de esos chicos, Juan, Lucía, Martina, o mejor, lo que sucede entre ese profesor y sus alumnos Juan, Lucía, Martina. Una mirada asombrada en el encuentro de aquello que puede acontecer... Esa mirada que se construye de extrañeza, pero también de implicación y empatía, pasional, inquieta, implicada en un juego de identidad y 
diferencia. Una mirada de aceptación, también abierta la variabilidad de nuestras emociones, que hace sitio a la singularidad de una experiencia.

Es que tal vez, sólo al calor de los encuentros sea posible perder la estabilidad del propio punto de vista, o tan siquiera, por esa especie de inquietud y desprotección que sentimos apenas al intuir que

\footnotetext{
“...el lenguaje no es ni la verdad ni el tiempo, ni la eternidad ni el hombre, sino la forma siempre deshecha del afuera; sirve para comunicar, o mejor aún deja ver en el relámpago de su oscilación indefinida, el origen y la muerte, -su contacto de un instante mantenido en un espacio desmesurado." (FOUCAULT, 1989: 80).
}

\section{Bibliografía.}

BARTHES R. Lo obvio y lo obtuso. BS.AS: Paidós, 1982;

DUSSEL, INÉS; CARUSO, MARCELO. La invención del aula: una genealogía de las formas de enseñar. Buenos Aires: Santillana, 2006;

GADAMER, G.-H., Verdad y método,II. Salamanca, Sígueme, 1997.

FOUCAULT, M; El pensamiento del afuera, Valencia, Pre-textos, 1989;

HONG, P. Los fronterizos. Barcelona, Tusquets, 1993;

GONZÁLEZ, H; RINISI, E.y FERRER,C. “¿Se puede salvar la teoría?”. El Ojo Mocho Revista de Crítica Cultural, N 5: 3-6, Argentina,1994;

LARROSA, J. Entre lenguas. Lenguaje y educación después de Babel, LEARTES, 2003;

LARROSA, J. y SKLIAR, C. (comp) Experiencia y Alteridad en educación. Homo Sapiens, 2009;

LIZCANO, E. Metáforas que nos piensan. Sobre ciencia, democracia y otras poderosas ficciones. Madrid: Ed. Bajo Cero/Traficantes de Sueños, 2006; reed. en Buenos Aires: Biblos, 2009);

LARRAURI, M.; El deseo según Deleuze. Ed. Tándem València, 2000;

MEIRRIE, P; Frankenstein Educador Barcelona: Ed. Laertes, 1998;

NIETZSCHE, F. Sobre verdad y mentira en sentido extramoral. Madrid, Editorial Tecnos, 1998;

RATTERO, C. Ser maestro ¿vale la pena? Ministerio de Educación Ciencia y Tecnología. Dirección Nacional de Gestión Curricular y Formación Docente. portal.educacion.gov.ar/inicial/files/2009/12/sermaestro_rattero.pdf, 2007;

RATTERO, C. (comp) La escuela inquieta. Buenos Aires: Noveduc. 2013. 
${ }^{\text {i } U n i v e r s i d a d ~ N a c i o n a l ~ d e ~ E n t r e ~ R i ́ o s-A r g e n t i n a: ~ c a r i n a . r a t t e r o @ h o t m a i l . c o m ~}$

${ }^{\text {ii }}$ Las primeras definiciones de pedagogía diferenciaban al pedagogo- ayo que cría al niño-, del pedante- maestro que enseña a los niños- veáse Dussel, Inés; Caruso, Marcelo. (2006). La invención del aula: una genealogía de las formas de enseñar. Buenos Aires: Santillana. pag 15 y 16

${ }^{\text {iii }}$ El orden del discurso pedagógico - y lo que llamamos la práctica o la realidad- está configurado por 'una hueste en movimiento de metáforas, metonimias, que, como decía Nietzsche, han olvidado que lo son.

iv González, Rinesi, Ferrer: “Se puede salvar la teoría?” Revista “El Ojo Mocho”, № 5, Buenos Aires, 1.994.

${ }^{\mathrm{v}}$ Diccionario Real academia, consulta on line.

${ }^{\text {vi }}$ Los testimonios surgen de mis notas de clase como profesora de Didáctica III. FCE UNER. Bitácoras de ayudantías docentes en escuelas e institutos de formación docente.

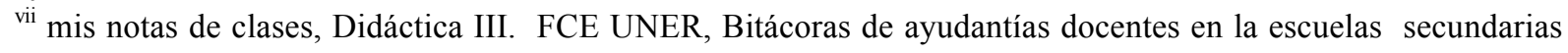
de Paraná, 2012.

viii Hong, p. Los fronterizos.(1993) Tusquets. pág 66.

${ }^{\text {ix }}$ Borrarse -nos dice Deleuze- es hacer como la Pantera Rosa que pintaba la pared que había detrás de ella de color rosa y, de esta manera, pasaba inadvertida. Veáse Larrauri Maite (2000) El deseo según Deleuze. Ed. Tándem València. 